Article

\title{
Dynamic Response Analysis of Rutting Resistance Performance of High Modulus Asphalt Concrete Pavement
}

\author{
Chundi Si ${ }^{1,2, *}$, Hang Cao ${ }^{1}$, Enli Chen ${ }^{1}$, Zhanping You ${ }^{2}{ }^{\oplus}$, Ruilan Tian ${ }^{1, *}$, Ran Zhang ${ }^{2,3}$ \\ and Junfeng $\mathrm{Gao}^{3}{ }^{3}$ \\ 1 Institute of Transportation Environment and Safety Engineering, Shijiazhuang Tiedao University, \\ Shijiazhuang 050043, Hebei, China; schundi@mtu.edu (H.C.); chenenl@stdu.edu.cn (E.C.) \\ 2 Department of Civil and Environmental Engineering, Michigan Technological University, \\ Houghton, MI 49931, USA; zyou@mtu.edu (Z.Y.); ranzhang@mtu.edu (R.Z.) \\ 3 School of Highway, Chang'an University, South Erhuan Middle Section, Xi'an 710064, Shaanxi, China; \\ junfengg@mtu.edu \\ * Correspondence: sichundi@stdu.edu.cn (C.S.); tianrl@stdu.edu.cn (R.T.)
}

Received: 21 October 2018; Accepted: 12 December 2018; Published: 19 December 2018

Featured Application: This study of the dynamic response of rutting resistance of high modulus asphalt concrete pavement will lay a foundation for the performance research and further engineering practice of high modulus asphalt concrete.

\begin{abstract}
In order to systematically study the rutting resistance performance of High-Modulus Asphalt Concrete (HMAC) pavements, a finite element method model of HMAC pavement was established using ABAQUS software. Based on the viscoelasticity theory of asphalt, the stress and deformation distribution characteristics of HMAC pavement were studied and compared to conventional asphalt pavement under moving loads. Then, the pavement temperature field model was established to study the temperature variation and the thermal stress in HMAC pavement. Finally, under the condition of continuous temperature variation, the creep behavior and permanent deformation of HMAC pavement were investigated. The results showed that under the action of moving loads, the strain and displacement generated in HMAC pavement were lower than those in conventional asphalt pavement. The upper surface layer was most obviously affected by outside air temperature, resulting in maximum thermal stress. Lastly, under the condition of continuous temperature change, HMAC pavement could greatly reduce the deformation of asphalt material in each surface layer compared to conventional asphalt pavement.
\end{abstract}

Keywords: HMAC; dynamic response; moving load; temperature field; rutting resistance; the permanent deformation

\section{Introduction}

Due to the heavy-duty vehicle traffic and frequency of hot weather, rutting damage of pavement has become increasingly prominent. In recent years, road researchers have explored many approaches to prevent rutting effectively. High-modulus asphalt concrete (HMAC) was first used in France to improve the modulus of pavement, and has gained increasing application in the road industry. In 1980, HMAC was first applied to road reinforcement and maintenance [1]. After that, with the fuel crisis, HMAC was applied more to both the base and surface layers of new roads. The standard for construction and design of the high modulus asphalt pavement was proposed by the French researchers in 1992. During the 1990s, the French P.R. INDUSTRI Co. developed the PR-module 
type high modulus admixture for asphalt pavement. Due to the convenience of application and the favorable impact on road performance, the PR-type high-modulus admixture has been widely applied. In 1999, a French researcher conducted a long-term monitoring of the performance of asphalt pavement with low-grade asphalt binder. It was found that the use of a high-modulus admixture along with low-grade asphalt binder is a cost-effective method to enhance the rutting resistance of pavement. The low-grade asphalt binder with high-modulus admixture has been widely applied as the lower surface layer of pavement [2]. Since 2004, a lot of studies have been performed on the HAMC by the LCPC (Laboratoire Central des Ponts et Chaussées) organization of France [3].

After decades of development, high-modulus asphalt mixtures have been divided into two types in French: the high-modulus asphalt mixture surface layer (EME) and the high-modulus asphalt mixture base layer (BBME). According to the quality requirement for the high-modulus asphalt mixture, the standards NF-P98-140 (1992) [4], NF-P98-141(1993) [5], and NF EN13108-1-2007 [6] for high-modulus asphalt mixture were built by French research scholars. The applied layer and related performance requirement for the high-modulus asphalt mixture have been identified. These standards were built based on the field application, and provide technical guidance for pavement construction.

Various researchers have investigated the HMAC for field application. England investigated the high modulus asphalt binder and the related mixture based on field applications of test roads. A long-term project was conducted that determined that the anti-aging performance and moisture susceptibility of HMAC are inferior. The project was conducted by Scott Wilson Engineering Consultants Ltd. and the University of Nottingham; then, a designed standard for England was proposed based on this project [7]. In Italy, the road performance and effect of HMAC was analyzed, and the benefits of HMAC as a base layer were identified [8]. Some Portuguese researchers studied the rutting resistance of the high-modulus asphalt mixture based on the high-temperature climate [9]. Some researchers in United States (USA) also studied the design methods and analyzed the cost analysis of the HMAC $[10,11]$. After long-term and meticulous research, the Transportation Research Board (TRB) of the US proposed a long-life asphalt pavement design theory. In this theory, the HMAC was used in the middle surface layer of the long-life pavement structure, and the modified asphalt was used to increase the modulus [12].

Lee et al. [13] prepared the HMAC by using the SBS (Styrene-Butadiene-Styrene) modified asphalt binder and high softening point oil, and found that the HMAC has better rutting resistance. European research on the high-modulus asphalt mixture test section showed that there was an insignificant correlation between pavement cracking and the grade of asphalt. The low-grade asphalt has little impact on cracking phenomena, while it significantly contributes to the improvement of rutting resistance [14]. Rodrigo et al. [15] analyzed the strength modulus, adhesion, stability, rutting resistance, and anti-aging performance of the mixture. Espersson et al. [16] studied the influence of temperature on the performance of high-modulus asphalt mixture. It was found that under the condition of high temperatures, HMAC could reduce the required pavement thickness.

Compared with foreign countries, the research on HMAC pavement in China is still in its infancy. The cooperation between Jiangsu Transportation Research Institute and the Cooper Co. proposed three key topics during the meeting in 2009: the origin, development, and current status of the high-modulus asphalt binder; the design methods and performance of the high-modulus asphalt mixture; and the process of how England adopt the high-modulus asphalt binder [17]. In addition, some scientific research institutes also studied the high-modulus asphalt mixture. In early 2007, Liaoning Academy of Transportation Sciences carried out the research on the application technology of HMAC, and paved a test HMAC surface road on Liaofeng highway in Liaoyang City [18]. The Liaoning transportation research institute proposed the standard 'Construction Technical Specification of High Modulus Asphalt Mixture (DB 21/T1754-2009)' [19], which has provided technical support for the actual application of HMAC in Liaoning province. AiminSha et al. [20] improved the performance of HMAC by adjusting the gradation of mixture design, especially the dosage of mine powder, and adding high-molecular additives. As a result, the resilient modulus at $20^{\circ} \mathrm{C}$ of HMAC increased by 
about $45 \%$. Jianlong Zheng, et al. [21] studied the pavement material design and the construction technique of HMAC under heavy traffic loading condition, and revealed the mechanical mechanism that could improve the road performance of HMAC. Ouyang Wei et al. [22] developed HMAC materials through experiments, and applied them to the middle surface layer, which has the greatest impact on pavement rutting, thus greatly improving the rutting resistance of asphalt pavement. Guangdong Road and Bridge Construction Development Corporation, in cooperation with South China University of Technology, built a HMAC pavement test section of about $1.4 \mathrm{~km}$ on the Beijing-Zhuhai highway. After two years of operation, the test road was exposed to high-temperature conditions, and remained in good condition [23]. Analyzing the force behavior of the conventional road structure with a HMAC layer is still necessary in order to understand rutting resistance performance of the high-modulus asphalt concrete.

In this study, the stress and temperature fields of HMAC pavement compared to conventional asphalt pavement under moving load were analyzed in ABAQUS (Rhode Island, RI, USA). Then, under the condition of continuous temperature variation, the creep and permanent behavior were studied to show the characteristics of rutting deformation resistance in the HMAC pavement structure.

\section{Materials and HMAC Pavement Model}

\subsection{Materials}

The pavement structure is from a HMAC pavement test section of a highway in Baoding city of Hebei Province, China. Two different middle surface layers, AC-20 and HMAC-20, were compared. The gradations of AC-20 and HMAC-20 were the same, as shown in Table 1. The aggregates with particle sizes between $10-15 \mathrm{~mm}$ were basalt, and the aggregates with other particle sizes were limestone. The matrix asphalt used in AC-20 was 70\#, while in HMAC-20 it was 20\#; the basic properties of asphalt 70\# and 20\# are shown in Tables 2 and 3, respectively. The asphalt-aggregate ratios were determined as $4.4 \%$ in AC-20 and 3.8\% in HMAC-20 by the Chinese specifications JTG E20-2011 [24] and JTG D50-2006 [25]. The pavement structure and corresponding material parameters based on test are shown in Table 4.

Table 1. Gradation of AC-20 and high-modulus asphalt concrete (HMAC)-20.

\begin{tabular}{ccccccccccccc}
\hline Sieve Size (mm) & 26.5 & 19.0 & 16.0 & 13.2 & 9.5 & 4.75 & 2.36 & 1.18 & 0.6 & 0.3 & 0.15 & 0.075 \\
\hline Rate of Passing (\%) & 100 & 97.5 & 86.0 & 74.0 & 64.0 & 44.0 & 30.0 & 20.5 & 15.0 & 11.0 & 8.0 & 6.0 \\
\hline
\end{tabular}

Table 2. Basic properties of 20\# matrix asphalt.

\begin{tabular}{ccc}
\hline Index & Measured Value & Requirement \\
\hline Penetration at $25^{\circ} \mathrm{C}(0.1 \mathrm{~mm})$ & 19.9 & $15 \sim 25$ \\
Dynamic viscosity at $60^{\circ} \mathrm{C}(\mathrm{Pa} \cdot \mathrm{s})$ & 2918 & $\geq 550$ \\
Softening point $\left({ }^{\circ} \mathrm{C}\right)$ & 64.6 & $55 \sim 71$ \\
\hline
\end{tabular}

Table 3. Basic properties of 70\# matrix asphalt.

\begin{tabular}{ccc}
\hline Index & Measured Value & Requirement \\
\hline Penetration at $25^{\circ} \mathrm{C}(0.1 \mathrm{~mm})$ & 66 & $60 \sim 80$ \\
Penetration index & -0.3 & $-1.5 \sim 1.0$ \\
Softening point $\left({ }^{\circ} \mathrm{C}\right)$ & 47.5 & $\geq 46$ \\
Flash point $\left({ }^{\circ} \mathrm{C}\right)$ & 322 & $\geq 260$ \\
\hline
\end{tabular}


Table 4. Material parameters of HMAC pavement.

\begin{tabular}{cccccc}
\hline Structural Layer & $\begin{array}{c}\text { Thick-Ness } \\
(\mathbf{m m})\end{array}$ & $\begin{array}{c}\text { Density } \\
\left(\mathbf{k g} \cdot \mathbf{m}^{-3}\right)\end{array}$ & $\begin{array}{c}\text { Compressive Resilient } \\
\text { Modulus (MPa) }\end{array}$ & $\begin{array}{c}\text { Poisson's } \\
\text { Ratio }\end{array}$ & $\begin{array}{c}\text { Damping } \\
\text { Coefficient } \boldsymbol{\alpha}\end{array}$ \\
\hline AC-13 & 4 & 2500 & 1200 & 0.35 & 0.8 \\
HMAC-20 & 6 & 2500 & 2000 & 0.30 & 0.8 \\
ATB-25 & 8 & 2450 & 800 & 0.30 & 0.8 \\
Cement treated base (CTB) & 34 & 2400 & 1400 & 0.25 & 0.8 \\
Lime fly ash treated base (LFTB) & 20 & 1800 & 600 & 0.25 & 0.8 \\
Soil & - & 1850 & 40 & 0.40 & 0.8 \\
\hline
\end{tabular}

Note: 1 . The compressive resilient moduli are from the uniaxial compressive test based on the standard JTG D50-2006 at $20^{\circ} \mathrm{C}$. 2. ATB-25 means Asphalt-Stabilized Macadam.

\subsection{HMAC Pavement Model}

A finite element model based on the software ABAQUS(TM) V6.13 (2013) by Dassault Systèmes ${ }^{\circledR}$ (Rhode Island, RI, USA) was established (ABAQUS is one of the most powerful numerical simulation tools in the world. It can simulate the performance of most typical engineering materials and can be used to solve the problems in the field of road engineering) [26,27]. The assumptions about the road model were made as follows [28,29]. (1) The asphalt pavement surface was made of viscoelastic materials, and the remaining layers were made of linear elastic materials. (2) Structural layers were of uniform thickness, as well as isotropic and continuous without considering the influence of gravity. (3) The surface of the road was considered to be a horizontal plane, regardless of its roughness and the influence of the horizontal and vertical slopes. (4) The structural layers were completely continuous, and the displacement was continuous in the vertical direction.

In order to accurately simulate the viscoelasticity of asphalt materials, the viscoelastic parameters based on the Burgers model that were measured in the actual experiment were converted to Prony series [30]. These parameters, which were used in ABAQUS software, are shown in Table 5.

Table 5. Prony parameters in the Burgers model.

\begin{tabular}{ccccc}
\hline \multirow{2}{*}{ Structural Layer } & \multicolumn{4}{c}{ Prony Series } \\
\cline { 2 - 5 } & $g_{\mathbf{1}}$ & $\boldsymbol{g}_{\mathbf{2}}$ & $\boldsymbol{\tau}_{\mathbf{1}}$ & $\boldsymbol{\tau}_{\mathbf{2}}$ \\
\hline AC-13 & 0.38 & 0.62 & 1596.17 & 36.78 \\
HMAC-20 & 0.18 & 0.82 & 24526.03 & 170.58 \\
ATB-25 & 0.39 & 0.61 & 1015.55 & 43.04 \\
\hline
\end{tabular}

The three-dimensional structure of the asphalt pavement was established by using ABAQUS. Due to the symmetry of the pavement structure and load, the $1 / 2$ model was taken for analysis, and the following dimensions of the pavement model were established: length (z-direction) was eight meters, width (x-direction) was six meters, and thickness (y-direction) was three meters. The C3D8R element was used in the grid-drawing process. The gridding of the mobile zone was refined across a section of the width and along the length and thickness of the model. Gradual refinement of the grid structure was made from the base to the surface of the pavement model, as shown in Figure 1.

The boundary conditions were set as follows: (1) the fully fixed constraint was applied to the subgrade of the road; (2) displacement of the four sides of the model was constrained; and (3) symmetrical constraints were applied to the symmetrical planes. 


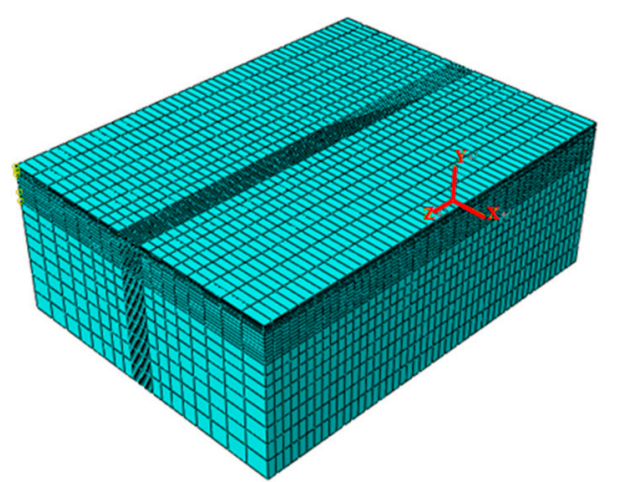

Figure 1. Finite element model of pavement structure.

\subsection{Distribution and Application of Moving Loads}

The standard axle load BZZ-100 was adopted, and the equivalent ground contact area of the load was $0.213 \mathrm{~m} \times 0.167 \mathrm{~m}$ with the axle load of $100 \mathrm{kN}$, which is the vertical uniform rectangular load. Due to the symmetry of the wheels on both sides of the vehicle and the negligible influence they had on each other during driving, only the left side of the axle was analyzed during the simulation. The loading regions (between the tires and the roadway) are shown in Figure 2. Measurements were taken under three points: point $A$, between the loading regions; point $B$, in the center of one of the loading regions; and point $C$, at the outer edge of one of the loading regions. FORTRAN language was used to program an ABAQUS external subroutine, VDLOAD, to move the vehicle load $60 \mathrm{~km} / \mathrm{h}$ along the moving belt [31].

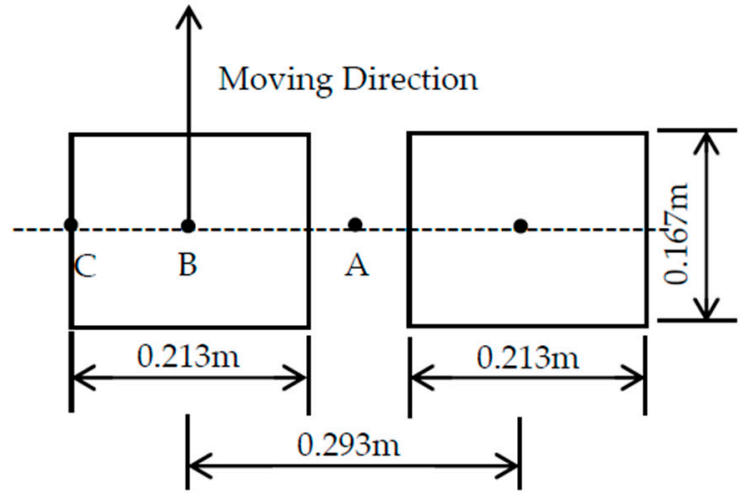

Figure 2. Diagram of loading regions.

\section{Comparison of Mechanical Properties of HMAC and Conventional Asphalt Pavement}

The structure of the conventional asphalt pavement that was used in this study was identical to the structure of HMAC pavement, except for the middle surface layer. The high-modulus structural layer in HMAC pavement was located in the middle surface layer, while the middle surface layer in the conventional asphalt pavement was composed of the ordinary material, AC-20. The specific parameters of these materials were determined by referring to literature [32], as shown in Table 6.

Table 6. Comparison of material parameters in the middle surface layer.

\begin{tabular}{|c|c|c|c|c|c|c|c|c|c|}
\hline $\begin{array}{l}\text { The Middle } \\
\text { Surface Layer }\end{array}$ & $\begin{array}{l}\text { Thickness } \\
(\mathrm{mm})\end{array}$ & $\begin{array}{l}\text { Density } \\
\left(\mathrm{kg} \cdot \mathrm{m}^{-3}\right)\end{array}$ & $\begin{array}{c}\text { Resilient } \\
\text { Modulus } \\
\text { (MPa) }\end{array}$ & $\begin{array}{l}\text { Poisson's } \\
\text { Ratio }\end{array}$ & $\begin{array}{c}\text { Damping } \\
\text { Coefficient } \alpha\end{array}$ & $g_{1}$ & $g_{2}$ & $\tau_{1}$ & $\tau_{2}$ \\
\hline AC-20 & 6 & 2500 & 1000 & 0.35 & 0.8 & 0.37 & 0.63 & 621.07 & 20.45 \\
\hline HMAC-20 & 6 & 2500 & 2000 & 0.30 & 0.8 & 0.18 & 0.82 & 24526.03 & 170.58 \\
\hline
\end{tabular}


The vertical stress, vertical strain, and vertical displacement at the upper surface layer were analyzed, as well as the shear stress and the shear strain at the middle surface layer. These measurements were taken underneath point B in Figure 2: that is, underneath the center of the leftmost tire of the vehicle. This data was compared to the conventional asphalt pavement. The dynamic response comparison results are shown in Figures 3-7.

Figures 3-7 show the following results:

Under the action of moving loads, the pattern variations of the five parameters were essentially the same between the two types of pavement. Compared to conventional asphalt pavement, the vertical stress and vertical shear stress in HMAC pavement were larger, while the vertical strain, vertical shear strain, and vertical displacement were smaller. This is consistent with the conclusion of reference $[33,34]$, which argued that the vertical stress of the upper surface layer of HMAC pavement is greater than that of conventional asphalt pavement.

The difference in the mechanical properties of HMAC pavement compared to conventional asphalt pavement are summarized as follows: the maximum vertical stress increased $7.96 \%$ from $326.11 \mathrm{kPa}$ to $352.07 \mathrm{kPa}$; the strain value decreased $24.5 \%$ from $-25.02 \mu \varepsilon$ to $-18.89 \mu \varepsilon$; and the vertical displacement decreased $18.8 \%$ from $0.16 \mathrm{~mm}$ to $0.13 \mathrm{~mm}$. It can be seen that the HMAC pavement has good resistance to vertical deformation.

Both the shear stress and the shear strain changed abruptly before and after the load passed the point of interest. Before the vehicle moved over the loading point, the maximum vertical shear stress of the middle surface layer compared to the conventional surface layer increased from $117.96 \mathrm{kPa}$ to $132.51 \mathrm{kPa}$, while the vertical shear strain decreased from $45.81 \mu \varepsilon$ to $30.80 \mu \varepsilon$. These relationships show that HMAC can be used to reduce the strain deformation caused by shear stress and effectively prevent the shear damage of the pavement.

Although the use of HMAC increased the stress in the surface layers, the strain decreased, which indicated that the rutting resistance ability of the asphalt pavement improved.

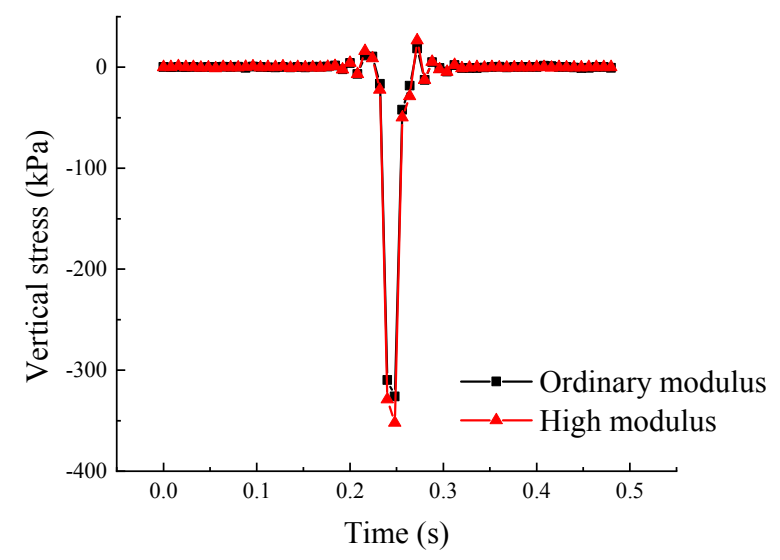

Figure 3. Comparison of vertical stress in the upper surface layer. 


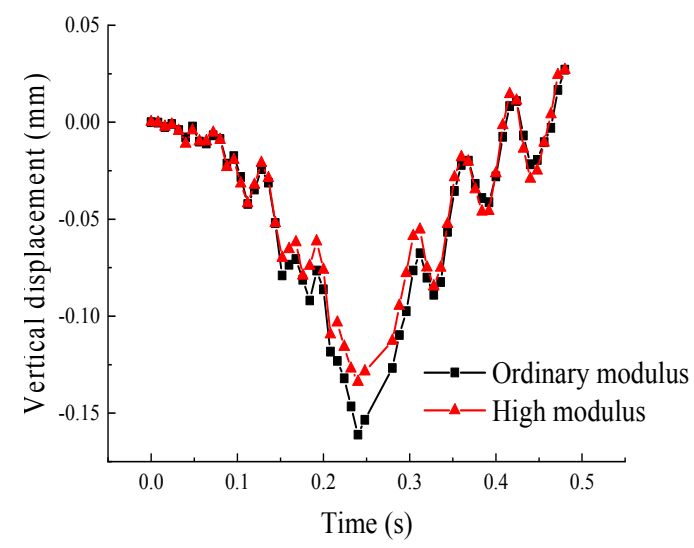

Figure 4. Comparison of vertical displacement in the upper surface layer.

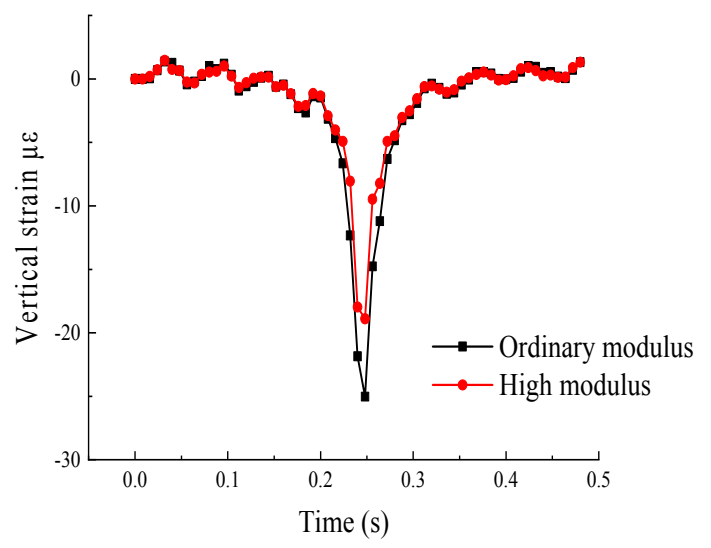

Figure 5. Comparison of vertical strain in the upper surface layer.

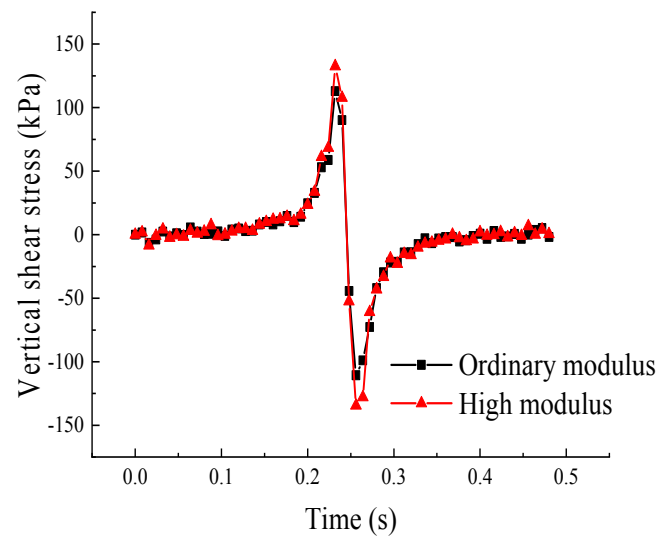

Figure 6. Comparison of vertical shear stress in the middle surface layer. 


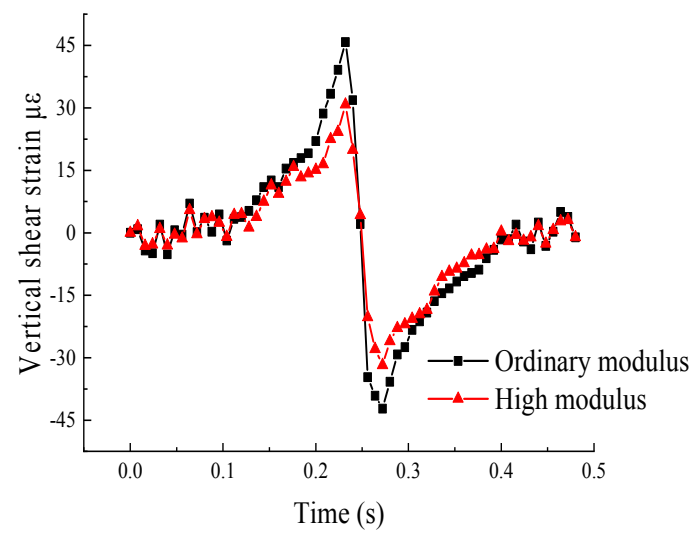

Figure 7. Comparison of vertical shear strain in the middle surface layer.

\section{Simulation of Temperature Field and Thermal Stress in HMAC Pavement}

\subsection{Analysis of Temperature Field}

The following assumptions were made in the establishment of the temperature field model: (1) the pavement layers were homogeneous and isotropic continua; (2) the temperature gradient in the horizontal direction was zero, and only the transfer of heat flow in the vertical direction was considered; and (3) there was continuous contact between the layers of the pavement, and the temperature and heat flow between the layers was continuous.

The temperature parameters of each layer of pavement materials were obtained from related literature [35-39]. The results are shown in Table 7.

Table 7. Temperature parameters of HMAC pavement.

\begin{tabular}{|c|c|c|c|c|c|c|c|}
\hline $\begin{array}{l}\text { Structural } \\
\text { Layer }\end{array}$ & $\begin{array}{c}\text { Depth } \\
(\mathrm{cm})\end{array}$ & $\begin{array}{c}\text { Density } \\
\left(\mathrm{kg} \cdot \mathrm{m}^{-3}\right)\end{array}$ & $\begin{array}{c}\text { Thermal } \\
\text { Conductivity } \\
\left(\mathrm{J} \cdot\left(\mathrm{m} \cdot \mathrm{h} \cdot{ }^{\circ} \mathrm{C}\right)^{-1}\right)\end{array}$ & $\begin{array}{l}\text { Heat Capacity } \\
\left(\mathrm{J} \cdot\left(\mathrm{kg} \cdot{ }^{\circ} \mathrm{C}\right)^{-1}\right)\end{array}$ & $\begin{array}{c}\text { Solar } \\
\text { Absorption } \\
\text { Coefficient } \alpha_{s}\end{array}$ & $\begin{array}{l}\text { Road Surface } \\
\text { Emissivity } \varepsilon\end{array}$ & $\begin{array}{c}\text { Absolute } \\
\text { Zero } \mathrm{T}_{\mathrm{Z}}\left({ }^{\circ} \mathrm{C}\right)\end{array}$ \\
\hline HMAC-20 & 10 & 2500 & 4680 & 925 & 0.9 & 0.81 & -273 \\
\hline ATB-25 & 18 & 2450 & 3600 & 800 & 0.9 & 0.81 & -273 \\
\hline СТВ & 52 & 2400 & 5600 & 910 & 0.9 & 0.81 & -273 \\
\hline
\end{tabular}

Air temperature data over a 24-h span in summer, as shown in Table 8, was applied in ABAQUS to calculate the temperature field of HMAC pavement. The temperature changes of each structural layer over the 24-h period are shown in Figure 8.

Table 8. Air temperature per hour over a 24-h span in summer.

\begin{tabular}{cccccc}
\hline Time (h) & $\begin{array}{c}\text { Air Temperature } \\
\left({ }^{\circ} \mathbf{C}\right)\end{array}$ & Time (h) & $\begin{array}{c}\text { Air Temperature } \\
\left({ }^{\circ} \mathbf{C}\right)\end{array}$ & Time (h) & $\begin{array}{c}\text { Air Temperature } \\
\left({ }^{\circ} \mathbf{C}\right)\end{array}$ \\
\hline 1 & 24.5 & 9 & 29.2 & 17 & 33.7 \\
2 & 23.7 & 10 & 31.8 & 18 & 32.1 \\
3 & 23.1 & 11 & 33.8 & 19 & 30.1 \\
4 & 22.6 & 12 & 35.6 & 20 & 29.8 \\
5 & 23.5 & 13 & 36.5 & 21 & 29.2 \\
6 & 24.0 & 14 & 38.1 & 22 & 27.5 \\
7 & 26.2 & 15 & 36.9 & 23 & 26.9 \\
8 & 27.2 & 16 & 34.7 & 24 & 25.2 \\
\hline
\end{tabular}




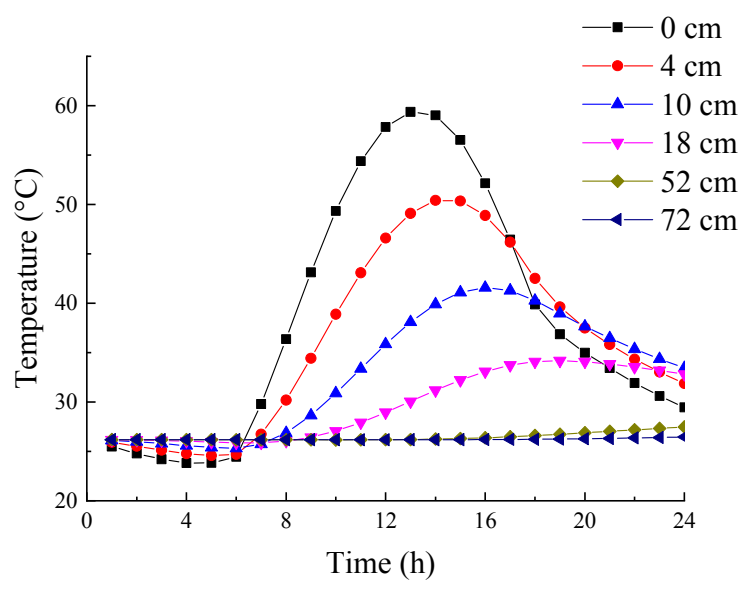

Figure 8. Temperature in each structural layer over $24 \mathrm{~h}$.

It can be seen from Figure 8 that the temperature changes varied with different depths in the pavement structure. From this data, several conclusions were made.

The upper and middle surface layers were most affected by the outside air temperature, which was essentially the same as the variations of the air temperature. With increasing depth, the influence of outside air temperature gradually decreased. The temperature in the LFTB layer, which was least affected by the outside air temperature, always stayed at approximately $27^{\circ} \mathrm{C}$. When the outside air temperature reached its highest point, $38.1^{\circ} \mathrm{C}$ at $14: 00$, the upper surface layer also reached the maximum value of approximately $59^{\circ} \mathrm{C}$. Due to the time delay of heat transfer, each structural layer reached the maximum temperature according to its depth beneath the surface, with the upper highest layer reaching the maximum temperature first. After 14:00, the temperature of each structural layer gradually decreased after reaching the maximum value. The road surface had the greatest overall change in temperature.

\subsection{Analysis of Thermal Stress}

With the periodic change in temperature, the stress due to thermal expansion and contraction in the pavement structure was calculated. In the calculation of the thermal stress, the temperature coefficients and elastic moduli were different at different temperatures, and the corresponding parameters of pavement materials were determined by the related literature [40-44], as shown in Tables 9 and 10. These parameters of the materials were automatically interpolated in ABAQUS according to the actual temperature at each point. The simulated thermal stress in different layers is shown in Figure 9.

Table 9. Thermal expansion coefficients of pavement materials.

\begin{tabular}{cccccc}
\hline \multirow{2}{*}{ Structural Layer } & \multicolumn{5}{c}{ Thermal Expansion Coefficient at Different Temperatures } \\
& \multicolumn{7}{c}{$\mathbf{( 1 0}^{-\mathbf{5}} \cdot{ }^{\circ} \mathbf{C}^{-\mathbf{1}} \mathbf{)}$} \\
\cline { 2 - 5 } & $\mathbf{2 0}{ }^{\circ} \mathbf{C}$ & $\mathbf{3 0}{ }^{\circ} \mathbf{C}$ & $\mathbf{4 0}{ }^{\circ} \mathbf{C}$ & $\mathbf{5 0}{ }^{\circ} \mathbf{C}$ & $\mathbf{6 0}{ }^{\circ} \mathbf{C}$ \\
\hline AC-13 & 2.0 & 2.2 & 2.4 & 2.5 & 2.7 \\
HMAC-20 & 1.4 & 1.6 & 1.7 & 1.8 & 1.9 \\
ATB-25 & & & 1.2 & & \\
CTB & & & 1.0 & & \\
LFTB & & 30 & & \\
Soil & & & & \\
\hline
\end{tabular}


Table 10. Material elastic parameters at different temperatures.

\begin{tabular}{ccccccccccc}
\hline \multirow{2}{*}{ Structural Layer } & \multicolumn{4}{c}{ Compressive Resilient Modulus $E \mathbf{~ ( M P a ) ~}$} & \multicolumn{4}{c}{ Poisson's Ratio $\boldsymbol{\mu}$} \\
\cline { 2 - 11 } & $\mathbf{2 0}{ }^{\circ} \mathbf{C}$ & $\mathbf{3 0}{ }^{\circ} \mathbf{C}$ & $\mathbf{4 0}{ }^{\circ} \mathbf{C}$ & $\mathbf{5 0}{ }^{\circ} \mathbf{C}$ & $\mathbf{6 0}^{\circ} \mathbf{C}$ & $\mathbf{2 0}^{\circ} \mathbf{C}$ & $\mathbf{3 0}{ }^{\circ} \mathbf{C}$ & $\mathbf{4 0}{ }^{\circ} \mathbf{C}$ & $\mathbf{5 0}^{\circ} \mathbf{C}$ & $\mathbf{6 0}^{\circ} \mathbf{C}$ \\
\hline AC-13 & 1200 & 960 & 850 & 730 & 660 & 0.35 & 0.40 & 0.40 & 0.45 & 0.45 \\
HMAC-20 & 2000 & 1650 & 1210 & 1080 & 870 & 0.30 & 0.30 & 0.35 & 0.40 & 0.45 \\
ATB-25 & 800 & 690 & 510 & 420 & 350 & 0.30 & 0.35 & 0.40 & 0.45 & 0.45 \\
\hline
\end{tabular}

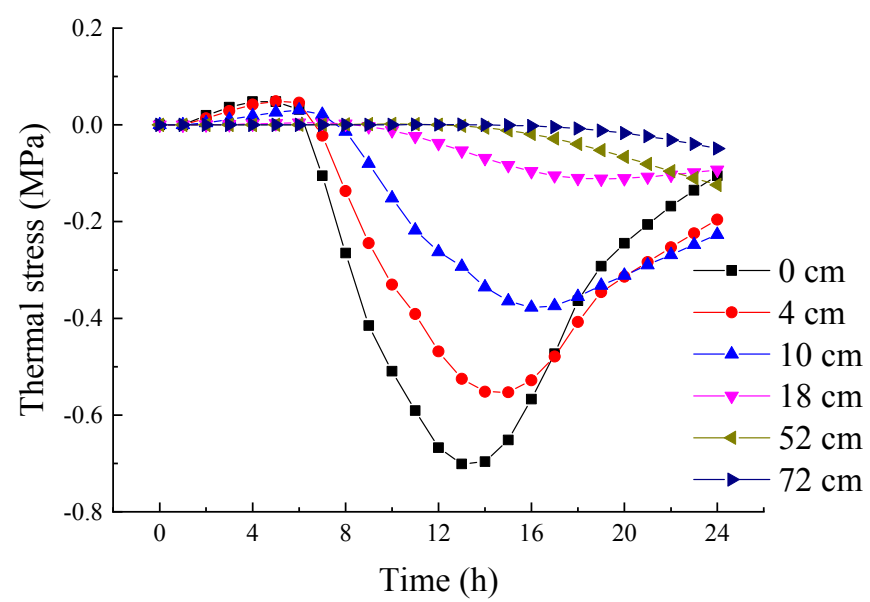

Figure 9. Thermal stress of each structural layer over $24 \mathrm{~h}$.

As shown in Figure 9, because of the decreasing of air temperature, tensile stress was generated by the shrinkage of pavement materials and reached its peak at about 4:00 from 0:00 to 6:00. In contrast, the pavement material began to expand, and generated compressive stress with the gradual increasing of air temperature after 6:00. The maximum compressive stress was reached at the same time as the maximum temperature.

Since the surface layers were most affected by the outside air temperature, the temperature field in these layers had the greatest change over the time period; therefore, the thermal stress in the surface layers had the greatest range of values. The maximum thermal stress appeared on the surface of the pavement and had a value of $-0.7 \mathrm{MPa}$. As the depth of the pavement increased, the thermal stress decreased continuously to approximately 0 in the base and sub-base layers. In hot summer, the maximum difference between tensile stress and compressive stress on the road surface within a day was about $0.75 \mathrm{MPa}$; the fatigue damage was easy accrued under the repeated action of thermal expansion and contraction.

Therefore, high temperature had a great impact on asphalt pavement, especially in the summer afternoon, during which the maximum temperature of the pavement surface almost reached $60^{\circ} \mathrm{C}$. Such temperatures will lead to the softening of asphalt pavement and the change of material properties; coupled with the repeating and heavy loading, fatigue damage could occur easily, which is also an important factor for rutting in the high-temperature season.

\section{Anti-Rutting Analysis of HMAC Pavement under Continuous Temperature Variation}

Rutting is generated by the combination of driving load and external environment. Based on a time-hardening creep model, the previously generated temperature field was introduced to analyze the formation process of rutting, and the rutting model was established under the condition of continuous temperature variation. By comparing the creep and permanent deformation of HMAC pavement with those of conventional asphalt pavement under moving loads, the rutting resistance characteristics of HMAC pavement were studied. 


\subsection{The Establishment of Rutting Calculation Model}

The deformation of asphalt pavement includes creep deformation and elastic deformation. Rutting is a severe road distress that is mainly caused by the creep deformation [45]. In this study, the time-hardening creep model was used to simulate the rutting.

The creep deformation of pavement $\left(\varepsilon_{c r}\right)$ is related to the temperature $(T)$, stress $(q)$, and time $(t)$, and was obtained from Equation (1):

$$
\varepsilon_{c r}=f(T, q, t)
$$

In this study, the Norton Bailey creep law was applied to simulate the creep characteristics of asphalt mixture under loading conditions. In the analysis process, the stress is assumed to be constant; as a result, the above equation can be expressed as:

$$
\varepsilon_{c r}=C_{1} q^{C_{2}} C^{C_{3}}
$$

where $q$ and $t$ refer to the stress and time, respectively; meanwhile, $C 1, C 2$, and $C 3$ are the temperature-dependent model parameters, and were determined based on the lab tests.

Furthermore, Equation (2) can be expressed as:

$$
\varepsilon_{c r}=A q^{n} t^{m}
$$

Equation (3) is the time-stress-creep model of ABAQUS, in which $A, m$, and $n$ are the model parameters:

$$
A=C_{1} C_{3}, n=C_{2}, m=C_{3}-1
$$

In order to simulate road rutting, the creep parameters of the asphalt surface layers were used in the model. The selected parameter values are shown in Table 11, based on references [45-49].

Table 11. Creep parameters of asphalt mixture at different temperatures.

\begin{tabular}{ccccc}
\hline \multirow{2}{*}{ Structural Layer } & Temperature $\left({ }^{\circ} \mathrm{C}\right)$ & \multicolumn{3}{c}{ Creep Parameter } \\
\cline { 3 - 5 } & & $\boldsymbol{A}$ & $\boldsymbol{n}$ & $\boldsymbol{m}$ \\
\hline \multirow{3}{*}{ AC-13 } & 20 & $6.54 \mathrm{E}-11$ & 0.937 & -0.592 \\
& 30 & $3.33 \mathrm{E}-09$ & 0.862 & -0.587 \\
& 40 & $1.45 \mathrm{E}-08$ & 0.792 & -0.577 \\
& 50 & $1.39 \mathrm{E}-06$ & 0.414 & -0.525 \\
HMAC-20 & 60 & $1.46 \mathrm{E}-05$ & 0.336 & -0.502 \\
\hline & 20 & $1.46 \mathrm{E}-12$ & 0.962 & -0.601 \\
& 30 & $5.80 \mathrm{E}-10$ & 0.896 & -0.599 \\
& 40 & $5.85 \mathrm{E}-09$ & 0.823 & -0.598 \\
ATB-25 & 50 & $6.10 \mathrm{E}-07$ & 0.415 & -0.532 \\
& 60 & $6.50 \mathrm{E}-06$ & 0.350 & -0.522 \\
\hline & 20 & $4.59 \mathrm{E}-11$ & 0.922 & -0.581 \\
& 30 & $3.46 \mathrm{E}-09$ & 0.859 & -0.576 \\
& 40 & $1.96 \mathrm{E}-08$ & 0.83 & -0.562 \\
& 50 & $1.20 \mathrm{E}-06$ & 0.322 & -0.522 \\
& 60 & $3.76 \mathrm{E}-05$ & 0.21 & -0.418 \\
\hline
\end{tabular}

In the analysis step module, 24 analysis steps, step- $1 \mathrm{~h}$ through step- $24 \mathrm{~h}$, were set. These step srepresented 24 hours in a day. In order to simulate the formation of rutting of asphalt pavement during a continuous temperature change in one day, the cumulative loading time of the pavement structure needed to be input into each analysis step. The cumulative loading time of the wheel load was calculated as follows:

$$
t=\frac{0.36 N P}{n_{w} p B v}
$$


where $t$ (s) is the cumulative loading time of the wheel load; $N$ is the number of wheel-loading cycles; $P(\mathrm{kN})$ is the axle weight of the vehicle; $n_{w}$ is number of tires on the axle; $p(\mathrm{MPa})$ is the tire contact pressure; $B(\mathrm{~cm})$ is the width of tire-ground contact; and $v(\mathrm{~km} / \mathrm{h})$ is driving speed.

According to the above formula, the required calculation parameters were determined, as shown in Table 12.

Table 12. Calculation parameters of rutting model.

\begin{tabular}{ccccccc}
\hline Calculation Parameters & $\boldsymbol{P ( \mathbf { k N } )}$ & $\boldsymbol{n}_{\mathrm{w}}$ & $\boldsymbol{B}(\mathbf{c m})$ & $\boldsymbol{N}\left(\times \mathbf{1 0}^{\mathbf{4}}\right)$ & $\boldsymbol{p ( \mathbf { M P a } )}$ & $\boldsymbol{V}\left(\mathbf{k m} \cdot \mathbf{h}^{-\mathbf{1}}\right)$ \\
\hline Value & 100 & 4 & 21.3 & 50 & 0.7 & 60 \\
\hline
\end{tabular}

Substituting the above parameters into Formula (5), it can be calculated that the time during which a one-wheel load acts on the road surface is $0.01006 \mathrm{~s}$, and the cumulative loading time for 500,000 -axle loads is $5030 \mathrm{~s}$. A traffic volume distribution of a certain section of road over 24 hours was selected, and an approximated value of the segmented cumulative loading time of each hour in one day was obtained, as shown in Table 13.

Table 13. Accumulated axial load time of at different time periods.

\begin{tabular}{ccc|ccc|cc}
\hline Time (h) & $\begin{array}{c}\text { Proportion } \\
\mathbf{( \% )}\end{array}$ & $\begin{array}{c}\text { Accumulated } \\
\text { Time (s) }\end{array}$ & Time (h) & \multicolumn{2}{c|}{$\begin{array}{c}\text { Proportion } \\
\mathbf{( \% )}\end{array}$} & $\begin{array}{c}\text { Accumulated } \\
\text { Time (s) }\end{array}$ & \multicolumn{2}{c}{ Time (h) } & $\begin{array}{c}\text { Proportion Accumulated } \\
\text { (\%) }\end{array}$ \\
\hline 1 & 1.027 & 51.65 & 9 & 2.874 & 144.60 & 17 & 9.034 \\
Time (s) & \\
2 & 0.821 & 41.30 & 10 & 4.517 & 227.20 & 18 & 7.802 \\
3 & 0.739 & 37.15 & 11 & 5.749 & 289.15 & 19 & 6.981 \\
4 & 0.411 & 20.65 & 12 & 7.391 & 371.80 & 20 & 4.927 \\
5 & 0.587 & 29.55 & 13 & 7.802 & 392.45 & 21 & 4.106 \\
6 & 0.821 & 41.30 & 14 & 6.57 & 330.45 & 22 & 3.696 \\
7 & 1.150 & 57.85 & 15 & 7.391 & 371.80 & 23 & 2.874 \\
8 & 2.053 & 103.25 & 16 & 8.623 & 433.75 & 24 & 2.053 \\
\hline
\end{tabular}

Two load belts were installed in the middle of the road surface to apply the moving load. In order to calculate the road rutting, the previously calculated temperature field data were introduced in each analysis step by editing the INP file in ABAQUS.

\subsection{Analysis of Creep Deformation at Different Depths of Pavement Structure}

Rutting is mainly caused by the internal compaction and deformation of the asphalt pavement structure. Therefore, in order to further study the deformation of each structural layer, the distribution of transverse and vertical creep strain at different depths underneath the wheel center point (because of symmetry, the leftmost wheel was selected) and the point directly between the left-side wheels (hereafter: "dual-wheel center") were studied. These points were referred to in Figure 2 as point B and point A, respectively. The results are shown in Figures 10 and 11.

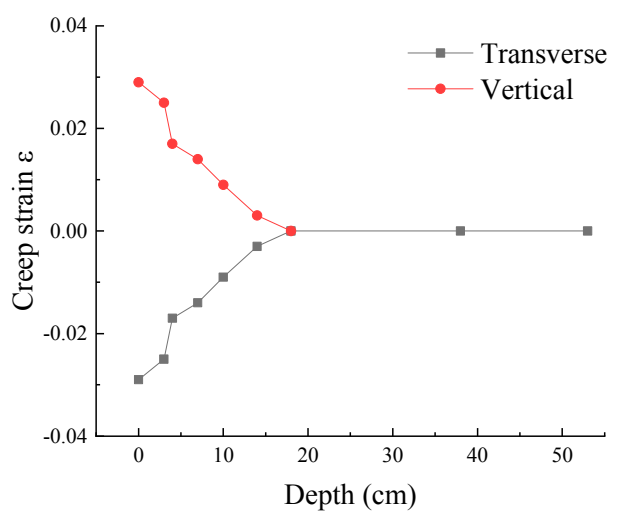

Figure 10. Distribution of creep strain at different depths under the center of the leftmost wheel. 


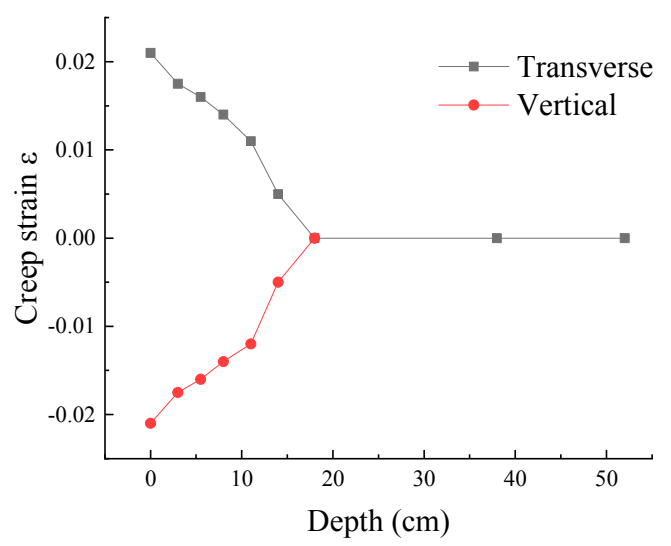

Figure 11. Distribution of creep strain at different depths under the left dual-wheel center.

As shown in Figures 10 and 11, the lateral and vertical creep strain of the structural layers underneath the road surface decreased with increasing depth, and were reduced to zero at $18 \mathrm{~cm}$. This means that the creep deformation only occurred in the surface layers. The maximum vertical and transverse creep strains were almost the same, and both appeared on the road surface. The maximum creep strain underneath the center of the leftmost wheel and the dual-wheel center were 0.021 and 0.028 respectively, and the pattern variations were consistent throughout the depth of the road.

At each reference point, the vertical creep and transverse creep had opposite signs. The vertical creep strain on the road surface below the leftmost wheel center was negative, which means compressive strain; meanwhile, the horizontal creep strain was positive, which means tensile strain. In contrast, the vertical creep strain on the road surface below the dual-wheel center was tensile strain, and the horizontal creep strain was a compressive strain.

\subsection{Comparison of Rutting Resistance between HMAC and Conventional Asphalt Pavement}

\subsubsection{Comparison of Permanent Deformation of Surface Layers}

In order to further analyze the rutting resistance performance of HMAC, the permanent deformation was simulated for both HMAC and conventional asphalt pavement. The material parameters of the middle surface layer in conventional asphalt pavement are shown in Table 14 . The permanent deformations are shown in Table 15 and Figures 12-14.

Table 14. Material parameters of middle surface layer of conventional asphalt pavement.

\begin{tabular}{ccccccc}
\hline \multirow{2}{*}{ Material } & \multirow{2}{*}{$\begin{array}{c}\text { Temperature } \\
\left({ }^{\circ} \mathbf{C}\right)\end{array}$} & $\begin{array}{c}\text { Elastic Parameters } \\
\text { Compressive Resilient } \\
\text { Modulus } \boldsymbol{E} \mathbf{( M P a )}\end{array}$ & $\begin{array}{c}\text { Poisson's } \\
\text { Ratio } \boldsymbol{\mu}\end{array}$ & $\boldsymbol{A}$ & $\boldsymbol{n}$ & $\boldsymbol{m}$ \\
& 20 & 1000 & 0.35 & $4.58 \mathrm{E}-11$ & 0.944 & -0.596 \\
& 30 & 830 & 0.35 & $2.46 \mathrm{E}-09$ & 0.796 & -0.585 \\
$\mathrm{AC}-20$ & 40 & 670 & 0.40 & $3.67 \mathrm{E}-08$ & 0.773 & -0.570 \\
& 50 & 530 & 0.45 & $4.80 \mathrm{E}-06$ & 0.595 & -0.532 \\
& 60 & 440 & 0.45 & $7.78 \mathrm{E}-05$ & 0.384 & -0.441 \\
\hline
\end{tabular}


Table 15. Material parameters of middle surface layer of conventional asphalt pavement.

\begin{tabular}{ccccc}
\hline Pavement Type & Depth $(\mathbf{c m})$ & $\begin{array}{c}\text { Deformation under } \\
\text { Point B (mm) }\end{array}$ & $\begin{array}{c}\text { Deformation under } \\
\text { Point A (mm) }\end{array}$ & $\begin{array}{c}\text { Maximum Relative } \\
\text { Deformation }(\mathbf{m m})\end{array}$ \\
\hline \multirow{3}{*}{ HMAC Pavement } & 0 & -2.57 & 1.14 & 3.71 \\
& 4 & -1.84 & 0.35 & 2.19 \\
\hline \multirow{2}{*}{ Conventional } & 0 & -1.05 & -0.36 & 1.05 \\
Asphalt Pavement & 4 & -6.25 & 4.59 & 10.84 \\
& 10 & -4.16 & 3.24 & 7.4 \\
\hline
\end{tabular}

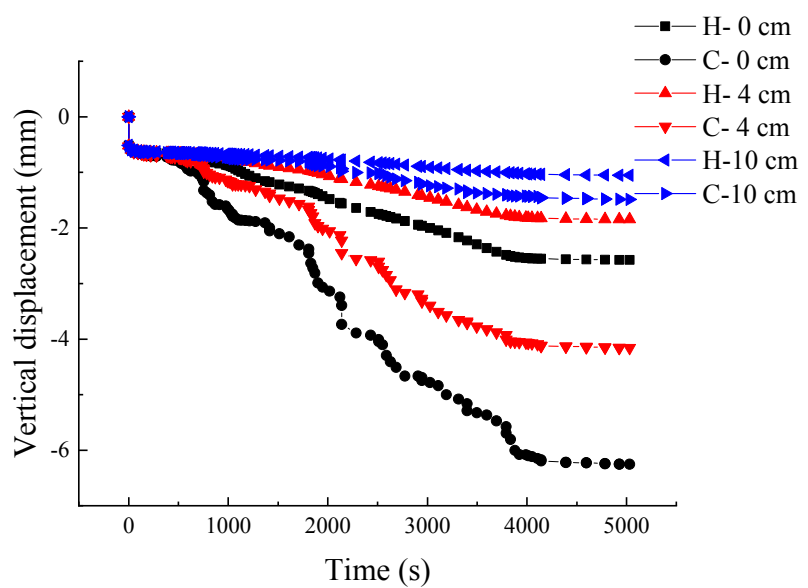

Figure 12. Comparison of vertical deformation at different depths underneath the center of the leftmost wheel.

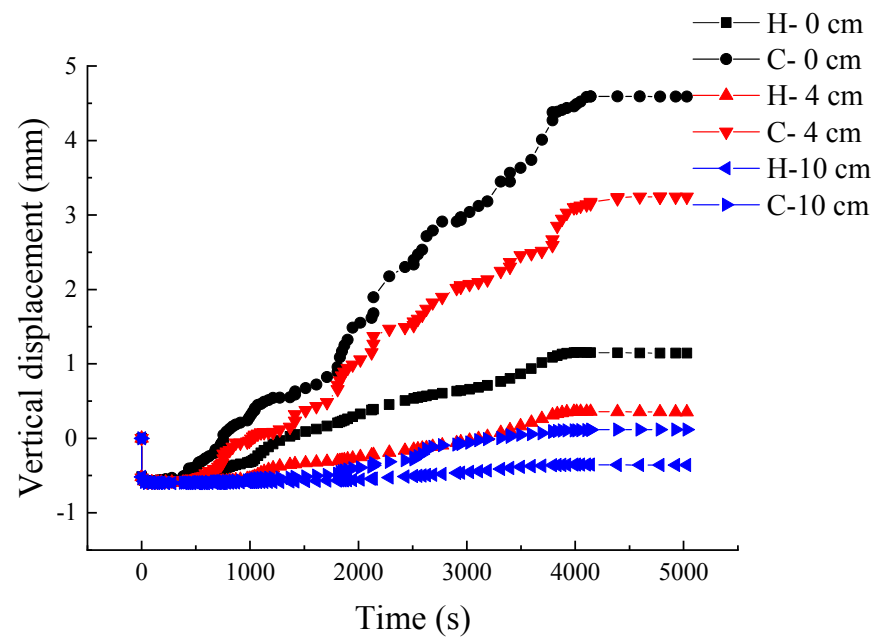

Figure 13. Comparison of vertical deformation at different depths underneath the dual-wheel center.

As shown in Figures 12 and 13, the internal deformation of conventional asphalt pavement changed with the increase of cumulative vehicle loading time, and its pattern variations were consistent with HMAC pavement. However, in the continuous temperature changing condition, the deformation curve of HMAC pavement fluctuated less with time and temperature, which was due to the low sensitivity of high modulus asphalt materials to temperature fluctuations. Therefore, the use of HMAC can reduce damage to the road surface caused by temperature changes.

Under continuous loading, with increasing depth, the difference in vertical displacement between HMAC pavement and conventional asphalt pavement decreased. The internal deformation of the conventional asphalt pavement increased at a faster rate, resulting in a larger difference with the 
permanent deformation of the HMAC pavement, and the deformation value of both permanent tended to be stable after $4000 \mathrm{~s}$.

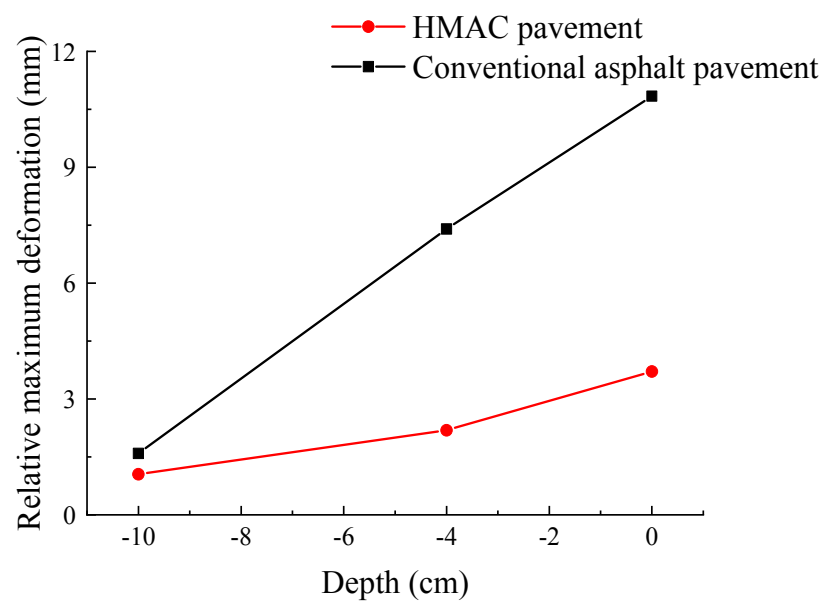

Figure 14. Comparison of the relative maximum deformation of two types of pavement at different depths.

From Table 15 and Figure 14, it can be seen that the deformation values of the conventional asphalt pavement at different depths were much higher than those of the HMAC pavement. At the road surface, the maximum relative deformation of conventional asphalt pavement was $10.84 \mathrm{~mm}$, which was $7.13 \mathrm{~mm}$ higher than that of HMAC, and the difference in deformation values was the largest. The second-highest difference in deformation was $5.21 \mathrm{~mm}$ at the bottom of the upper surface layer. At a depth of $10 \mathrm{~cm}$, although the vertical deformation was small, the maximum relative deformation of the conventional asphalt pavement was $1.59 \mathrm{~mm}$. This was an increase of $51.4 \%$ compared to the HMAC pavement. Therefore, the HMAC material can significantly reduce the permanent deformation of pavement.

In the conventional asphalt pavement, the maximum relative deformation generated in the middle surface layer was the largest, at $5.81 \mathrm{~mm}$. Therefore, the HMAC layer that was located in the middle surface layer could effectively reduce the relative deformation. Simultaneously, the deformation rate of the upper surface layer was also greatly reduced, thereby reducing the permanent deformation of the entire pavement.

To summarize, the permanent deformation of the two pavement structures mainly occurred in the upper and middle surface layers, while the settlement of HMAC in middle surface layer could effectively decrease the permanent deformation.

\subsubsection{Comparison of Permanent Pavement Deformation under Heavy Traffic}

Heavy traffic is a main cause for permanent deformation and the rutting distress of asphalt pavement. In order to further study the rutting resistance performance of HMAC pavement, a series of vehicle loads were applied to analyze the deformation of the two types of pavement. The result of this test is shown in Figure 15.

From Figure 15, it can be seen that as the tire contact pressure increased from 0.7 MPa to $1.5 \mathrm{MPa}$, the maximum relative deformation in both HMAC pavement and conventional asphalt pavement significantly increased; however, the maximum relative deformation of conventional asphalt pavement increased faster. When the tire contact pressure was $0.7 \mathrm{MPa}$, the maximum deformation of the conventional asphalt pavement was $7.13 \mathrm{~mm}$ higher than that of HMAC, and this value increased to $11.4 \mathrm{~mm}$ when the tire contact pressure was $1.5 \mathrm{MPa}$. Therefore, a heavy load is more harmful to the conventional pavement structure; HMAC pavement can effectively resist road deformation caused by heavy-duty loading and hot weather. 


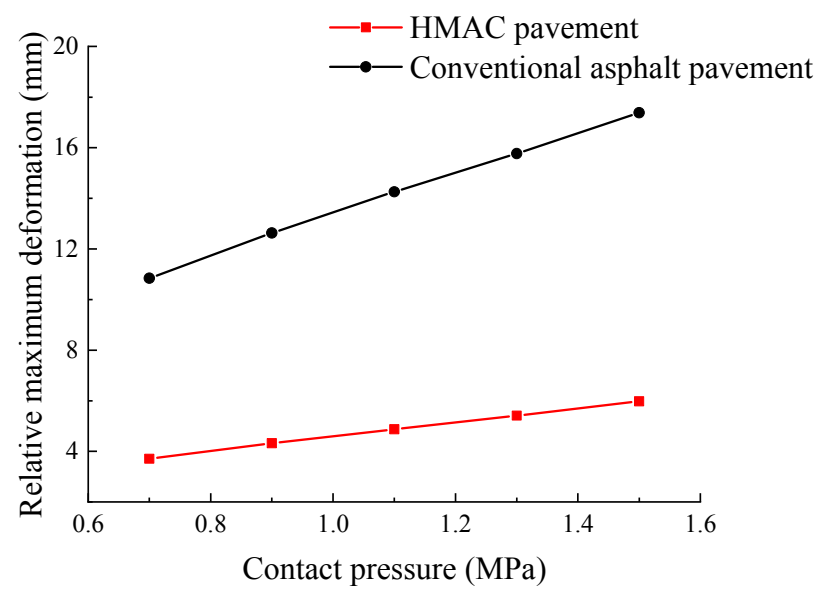

Figure 15. Comparison of maximum relative deformation at different tire contact pressure.

\section{Summary and Conclusions}

Based on the viscoelastic theory of asphalt, the finite element model in software ABAQUS was established according to the pavement structure and the material properties of the HMAC, the stress field and the temperature field was analyzed; then, the creep behavior and permanent deformation of the HMAC pavement was achieved. The following conclusions were obtained:

1. Compared to conventional asphalt pavement, vertical stress and shear stress generated in HMAC pavement increased, while the vertical strain, shear strain, and vertical displacement decreased. The vertical strain and the shear strain decreased by $24.5 \%$ and $32.8 \%$ respectively. The vertical displacement that was generated in the HMAC road surface also reduced from $0.16 \mathrm{~mm}$ to $0.13 \mathrm{~mm}$; this is an $18.8 \%$ reduction, which improved the evenness of the road surface.

2. The pattern variations of the temperature field and the thermal stress were consistent. When the surface temperature reached the maximum of $59^{\circ} \mathrm{C}$, the maximum thermal stress of $-0.7 \mathrm{MPa}$ was found. As the depth increased, the influence of outside air temperature on the pavement structural layers gradually decreased.

3. In both the HMAC pavement and conventional asphalt pavement, the creep deformation only occurred in the asphalt surface layers. At the road surface, the maximum relative deformation of conventional asphalt pavement reached $10.84 \mathrm{~mm}$, which was $7.13 \mathrm{~mm}$ higher compared to that of HMAC pavement. Therefore, the HMAC layer could effectively reduce the relative deformation of pavement.

4. With the increase of tire contact pressure from $0.7 \mathrm{MPa}$ to $1.5 \mathrm{MPa}$, the maximum relative deformation increased by $2.27 \mathrm{~mm}$ and $6.54 \mathrm{~mm}$ in HMAC pavement and conventional asphalt pavement, respectively. This suggested that HMAC pavement had better resistance to road deformation and rutting.

Author Contributions: Conceptualization, C.S.; methodology, E.C.; software and formal analysis, H.C.; validation, R.T.; writing —original draft preparation, H.C.; writing—review and editing, R.Z., Z.Y.; visualization, J.G.

Funding: This work was supported by the National Natural Science Foundation of China (No. 11202142, 11302138, and 11872253), Princal Project of Hebei Province Department of Transportation (No. Y-2010021, No 2013-2-5), Youth Talent Support Program of Hebei Province and Distinguished Young Scientists Foundation of Hebei Provincial Education Department (YQ2014038), Hebei science and technology project(18242219G).

Conflicts of Interest: The authors declare no conflict of interest.

\section{References}

1. Hermanssom, A. Mathematical model for paved surface summer and winter temperature, comparison of calculated and measured temperatures. J. ColdReg. Sci. Technol. 2004, 40, 1-17. 
2. Transportation Research Circular. Perpetual Bituminous Pavements: TRB Committeeon General Issues in Asphalt Technology; Number 503; Transportation Research Circular: Washington, DC, USA, 2001; pp. 12-31.

3. Kargarnovin, M.H.; Younesian, D. Response of beams on nonlinear viscoelastic foundations to harmonic moving loads. J. Comput. Struct. 2005, 83, 1865-1877. [CrossRef]

4. Couches Dassises: Enrobés à Module Élevé (EME); (NFP98-140); Renmin Communication Press: Paris, France, 1999.

5. Jean-Franeois, C. Development and Uses of Hard Grade Asphalt and of High Modulus Asphalt Mixes in France; Transportation Research Circular NO. 503; National Research Council: Washington, DC, USA, 2003; pp. 12-30.

6. Bituminous Mixtures-Material Specification-Part1: Asphalt Concrete; (NFEN13108-1:2007); Association Française de Normalisation: Paris, France, 2007.

7. Richard, E.; Scott, W. Implementing high modulus asphalt technology in the UK. In Proceedings of the International Seminar Maintenance Techniques to Improve Pavement Performance, Cancun, Mexico, 25-26 August 2009.

8. Pasetto, M.; Baldo, N. Permanent deformation of road and airport high performance asphalt concrete base courses. Adv. Mater. Res. 2013, 723, 494-502. [CrossRef]

9. Capitao, S.D.; Picado-Santos, L. Assessing permanent deformation resistance of high modulus asphalt mixtures. J. Transp. Eng. 2006, 132, 394-401. [CrossRef]

10. Sanders, P.J.; Nunn, M. The Application of Enrobe a Module Eleve in Flexible Pavements; Transport Research Laboratory: Crowthorne, UK, 2005.

11. Rys, D.; Judycki, J.; Pszczola, M.; Jaczewski, M.; Mejlun, L. Comparison of low-temperature cracks intensity on pavements with high modulus asphalt concrete and conventional asphalt concrete bases. Constr. Build. Mater. 2017, 147, 478-487. [CrossRef]

12. Zhao, Y.Q.; Ni, Y.B. Viscoelastic response solutions of multilayered asphalt pavements. J. Eng. Mech. 2014, 140, 04014080. [CrossRef]

13. Lee, H.J.; Lee, J.H.; Park, H.M. Performance evaluation of high modulus asphalt mixtures for long life asphalt pavements. Constr. Build. Mater. 2007, 21, 1079-1081. [CrossRef]

14. Maupin, G.W.; Diefenderfer, B.K. Design of a High-Binder-High-Modulus Asphalt Mixture. Princ. Res. Sci. 2007, 26, 42-48.

15. Miró, R.; Valdés, G.; Martínez, A.; Segura, P.; Rodríguez, C. Evaluation of high modulus mixture behaviour with high reclaimed asphalt pavement (RAP) percentages for sustainable road construction. Constr. Build. Mater. 2011, 25, 3854-3862. [CrossRef]

16. Espersson, M. Effect in the high modulus asphalt concrete with the temperature. J. Constr. Build. Mater. 2014, 71, 638-643. [CrossRef]

17. Peng, Y. Characteristic Behavior of High Modulus Asphalt and High Modulus Asphalt Mixtures. Master's Thesis, South China University of Technology, Guangzhou, China, 2012.

18. Yang, W.T. Research on the Technical performance with High Modulus Asphalt Concrete. Master's Thesis, Hebei University of Technology, Tianjin, China, 2011.

19. Construction Specification for High Modulus Asphalt Mixture; (DB21/T1754-2009); Renmin Communication Press: Shenyang, China, 2009.

20. Sha, A.M.; Zhou, Q.H.; Yang, Q. Material composition design method for high modulus asphalt concrete. J. Chang'an Univ. Nat. Sci. Ed. 2009, 3, 1-5.

21. Ma, J. Research on Characters of High Modulus Asphalt Concrete Pavement in Heavy Traffic Condition. Master's Thesis, Changsha University of Science and Technology, Changsha, China, 2011.

22. Ouyang, W. Study on Application Technology of High Modular Asphalt Concrete. Master's Thesis, Northeastern University, Shenyang, China, 2010.

23. Luo, L. Pavement Performance Study on the Hard Asphalt and Its Mixture. Master's Thesis, Changsha University of Science and Technology, Changsha, China, 2009.

24. Standard Test methods of Bitumen and Bituminous Mixtures for Highway Engineering; (JTGE20-2011); Ministry of Transport: Beijing, China, 2011.

25. Specifications for Design of Highway Asphalt Pavement; (JTGD50-2006); Ministry of Transport: Beijing, China, 2006. 
26. Zhuang, Z. Finite Element Analysis and Application Based on ABAQUS; Tsinghua University Press: Beijing, China, 2009.

27. Si, C.D.; Chen, E.L.; Fan, X.; Wang, Y.; Yu, S. Finite element simulation model of asphalt pavement based on ABAQUS. J. Graph. 2014, 35, 131-137.

28. Sousa, J.; Lysmer, J.; Monismtte, C.L. Eyelets of dynamic loads on performance of asphalt concrete pavements. J. Transp. Res. Rec. 1998, 13, 15-28.

29. White, T.D.; Zaghloul, S.M. Pavement analysis for moving aircraft load. J. Transp. Eng. 1997, 123, 436-446. [CrossRef]

30. Xu, L.; Zhao, Y.J. Finite elements analogy method for viscoelasticity of asphalt pavement. J. North. Transp. 2010, 6, 1-4.

31. Si, C.D.; Chen, E.L.; Yang, S.P.; Wang, Y.; Yu, S.W. Dynamic response of asphalt pavement considering coupling between fluid flow and stress under moving vehicle loads. J. Vib. Shock 2014, 33, 91-97.

32. Wang, F.S. A 3D fem analysis of creep deformation law of asphalt pavement based on burgers viscoelastic model. J. Ind. Build. 2014, 44, 104-109.

33. He, L.; Ling, T.Q. The influence of high modulus structure layer on fatigue performance of asphalt pavement. J. Traffic Sci. Technol. West 2016, 3, 6-11.

34. Yang, P. Study on the Properties of High Modulus Asphalt and Its Mixture. Ph.D. Thesis, South China University of Technology, Guangzhou, China, 2012.

35. Ren, D.B.; Su, B. Finite element analysis of temperature stress of asphalt pavement. J. Shenyang Jianzhu Univ. 2010, 26, 699-703.

36. Zhang, X.J.; Bai, C.L. Finite element analysis of temperature field and temperature stress of asphalt pavement. J. East China Highw. 2006, 5, 83-86.

37. Yan, Z.R. Temperature field analysis of layered pavement system. J. Tongji Univ. 1984, 3, 76-85.

38. Wu, G.C. Temperature Stress Analysis of Semi-Rigid Pavement; Science Press: Beijing, China, 1995.

39. Song, C.N. A survey of nonlinear temperature fields in layered pavement structures. J. Highw. 2005, 1, 49-54.

40. Wang, Z.F.; Zuo, L.; Mu, Y. Study on performance index of high modulus asphalt concrete and its application. J. Road Mach. Constr. Mech. 2017, 34, 64.

41. Qian, G.P.; Guo, Z.Y.; Zheng, J.L. Calculation of thermal viscoelastic temperature stress of asphalt pavement under environmental condition. J. Tongji Univ. 2003, 31, 150-155.

42. Zheng, M.; Li, P.; Yang, J.; Li, H.; Qiu, Y.; Zhang, Z. Fatigue life prediction of high modulus asphalt concrete based on the local stress-strain method. J. Appl. Sci. 2017, 7, 305. [CrossRef]

43. Li, P.; Zheng, M.; Wang, F.; Che, F.; Li, H.; Ma, Q.; Wang, Y. Laboratory performance evaluation of high modulus asphalt concrete modified with different additives. J. Adv. Mater. Sci. Eng. 2017, 2017, 7236153. [CrossRef]

44. Lv, S.T.; Fan, X.Y.; Xia, C.D.; Zheng, J.L.; Chen, D.; You, L.Y. Characteristics of moduli decay for the asphalt mixture under different loading conditions. J. Appl. Sci. 2018, 8, 840. [CrossRef]

45. Li, H.; Huang, X.M. Analysis of Analysis of asphalt rutting based on continuous temperature variation. J. Southeast Univ. 2007, 37, 916-920.

46. Zhang, Y.; Li, J.J. Numerical analysis of rut on high modulus asphalt pavement. J. Highw. Traffic Technol. 2010, 12, 53-55.

47. Yu, R.Y.; Yang, Y. Rutting analysis of new paved asphalt pavement considering heavy traffic vehicle restriction. J. China Foreign Highw. 2016, 1, 54-57.

48. Hu, L.L.; Lu, H.; Zhang, X.N. Comparison of module modulus of high modulus asphalt mixture. J. Highw. 2009, 7, 308-311.

49. Hua, J.F. Finite Element Modeling and Analysis of Accelerated Pavement Testing Devices and Rutting Phenomenon. Ph.D. Thesis, Purdue University, West Lafayette, Indiana, 2000.

(C) 2018 by the authors. Licensee MDPI, Basel, Switzerland. This article is an open access article distributed under the terms and conditions of the Creative Commons Attribution (CC BY) license (http:/ / creativecommons.org/licenses/by/4.0/). 